ISSN 1112-9867

\title{
SEXUAL HARASSMENT IN CAMPUS: AWARENESS, RISK FACTOR, AND EFFECT AMONG STUDENTS IN HIGHER LEARNING INSTITUTIONS
}

\author{
O. A. S. Rapidah ${ }^{1 *}$, S. N. Shafini ${ }^{1}$, M. A. Khalid ${ }^{1}$, M. Z. Masliza ${ }^{2}$, A. Nurulnadwan $^{3}$ \\ ${ }^{1}$ Faculty of Business and Management, Universiti Teknologi MARA, 23000 Dungun, \\ Terengganu, Malaysia \\ ${ }^{2}$ Academy of Language Studies, Universiti Teknologi MARA, 23000 Dungun, Terengganu, \\ Malaysia \\ ${ }^{3}$ Department of Research, Industrial Linkages, and Alumni, Universiti Teknologi MARA, \\ 23000 Dungun, Terengganu, Malaysia
}

Published online: 17 October 2017

\begin{abstract}
This study is an ongoing project related the problem of sexual harassment in academic setting. The objectives are (i) to determine the awareness of sexual harassment among students in higher learning institutions, (ii) to identify the existence of sexual harassment in higher learning institutions, and (iii) to investigate the risk factors contributed to the action. Questionnaires were distributed to 351 students in a public university in East Coast Malaysia. The findings revealed that $58.6 \%$ of the respondents have been harassed at least once and majority of them were female. The greatest form of sexual harassment experience by the respondents was offensive behavior followed by unwanted sexual attention while sexual coercion contributed least toward the act. Majority of the respondents agreed that sexual harassment experienced affected their emotional greatly compared to education and productivity.
\end{abstract}

Keywords: sexual harassment; students; higher learning institution

Author Correspondence, e-mail: sitirapidah@tganu.uitm.edu.my doihttp://dx.doi.org/10.4314/jfas.v9i5s.75 


\section{INTRODUCTION}

\subsection{Sexual Harassment}

The occurrence of sexual harassment often happens in a workplace setting and the act is abusing a person's personal comfort and integrity. United States Equal Employment Opportunity Commission (EEOC) defined sexual harassment as:

"Any act of unwanted sexual advances, demand for sexual advantage and other oral or physical conduct of a sexual nature establish sexual harassment when this conduct directly or indirectly affects and individual's employment, unreasonable interferences with and individual's job performance or makes and threatening, aggressive or violent work setting" [1].

In August 1999, the Code of Practice [2] on the Prevention and Eradication of Sexual Harassment has been launched by Ministry of Human Resource of Malaysia. The effort is to launch this code of practice among others are to define and highlight the issue of sexual harassment at work and it was the paramount effort by the government. This code defined the sexual harassment as any unwelcome conduct of a sexual nature which effect of oral, non-verbal, graphical, emotional or physical nuisance. The above definition stated that sexual harassment may be categorized as (i) sexual coercion and (ii) sexual annoyance. Sexual coercion may directly consequence the victim's job. For instance, where someone in a greater position who has the power over subordinate in term of remuneration or promotion, tries to intimidate a subordinate and demand for sexual favors. Job benefits will follow if the subordinate agrees to the superior's sexual request. On the contrary, job benefits are repudiated if the subordinates refuse [3]. Meanwhile, sexual annoyance is violent sexually-related behavior which victim feels it is threatening or hostile but has no effect to any job benefit. Nevertheless, the irritating behavior constructs an invonvenient working atmosphere which the victim has to accept in order to continue working [4].

\subsection{Sexual Harassemnt in Academic Setting}

Sexual harassment in campus is quite prevalent worldwide. Until recently, this issue has not become as recognized problem in college or university campuse. Students' enrollment in public higher education institution in Malaysia revealed a significant increase in female students. The phenomenons of women as a majority students in higher education institution in 
Malaysia also become a contributing factor lead to the incident of sexual harassment. The amounts of incident of sexual harassment in Malaysia do not greatly contrast from the condition found in the United States or other western countries [5] [14]. The presence of sexual harassment occurence in higher education in Malaysia had been revealed by a number of scholars in their experimental studies [6]. Attention from media regarding the sexual assault in university in recent years has also increased [7] [15]. Citing from [8], a professor in a university accused of sexual harassment of 14 students. He has been alleged in a federal complaint of having sexual affairs and consuming illegal drugs with students; making unsuitable, embarrassing or condescending remarks to female students and forcing them to meet with him alone. Meanwhile, in Australia, 6.9\% of students were sexually harassed at minimum one occasion in 2015 or 2016 [9] [16]. The act of sexual harassment involving students is so prevailing in Japan until it has been given its own acronym SHOC (Sexual Harassment on Campus) [18].

Experimental research related to sexual harassment in Malaysia has increased in recent years. The findings discovered that women have experienced sexual harassment at work was between $35 \%$ and $53 \%$ [10]. There were 75 cases reported involving employers while, 156 relating the colleagues [7]. It is observed that, it is largely connected with traditional employment and workplace situation, in which it includes mixed employment relationship [19] such as educational institutions as well. The problems of sexual harassment in colleges or universities have long been encountered by students or faculty members. It is doubting either these problems have been disregarded by higher learning institution for many years or dealt with it just by silently dismissing lecturers or instructors who have been accused of harassment or perhaps by shutting up the victims of such harassment. Students are differently with employees by nature transitory. Student's stake in institutional transformation may be short lived. Additionally, complaint may last well beyond the time spent by a student at a particular higher educational institution. Students are expected to reveal sexual harassment when they trust someone. Besides, students must be treated with respect, support provided, and qualified expert should be presented [11]. Then, the education institution should come out with comprehensive response plan to deal with the incident [10]. Students' observe institutions as having a greater attention in protecting faculty members, who have a more 
permanent relationship with the university, than in protecting temporary students. Thus, students may fear that the institution will reject the seriousness of a students' complaint against a faculty member [12]. It is stated in a current study, only fewer students in over 27 universities in America reported the incident of sexual violence experienced to an authorized source [2] [17].

One of the major predictor of sexual harassment is gender. Although there is an increasing number of men who experience sexual harassment and file complaints, women are still tremendously the aims of the act and men are most often the perpetrators [1]. As mentioned by [8] who acknowledged that lecturers easily take advantage on students but there are many female students especially who feel embarrassed to report the incident of sexual harassment. The frequent incident of sexual harassment in campus is due to a lecturer who takes advantage on students who need help such as adjustments of class timetable or during academic consultation session. [8] further stated that there is a lecturer who requests for sex rewards which the act violates the university ethics. Likewise, many victims of sexual harassment do not know the actual or proper channel to complaint about their problems and some even decided not to express it because of shame and fear. Students are ashamed of being dishonored and feel afraid because of the perpetrator is a lecturer who has the power to approve and frustrate their grades. Many research and discussion has been made on sexual harassment locally or worldwide related to workplace setting, yet only limited studies had been conducted widely in the higher education institution context in Malaysia. Therefore, the objectives of this study are (i) to determine the awareness of sexual harassment among students in higher learning institutions, (ii) to identify the existence of sexual harassment in higher learning institutions, and (iii) to investigate the risk factors contributed to the action. The next section discussed on the methodology involves in carried out this study.

\section{METHODOLOGY}

A set of 310 questionnaires was disseminated to male and female students in three branch campuses from all faculties. From the 310 questionnaires distributed, a total of 273 were accomplished and returned representating a response rate of $78 \%$. The respondents were selected using quota sampling technique. Descriptive analyses on the awareness of sexual 
harassment experienced, factors contributed to the incident as well as effect of sexual harassment were analysed. Pearson correlation coefficient was used to evaluate the relationship between variables. Further, multiple regression was used to examine the influence of independent variables towards dependent variable.

\section{FINDINGS AND DISCUSSION}

Descriptive information on respondent's profile indicated that, more than half of the respondents were female $(63.7 \%)$ while the remaining were male. Majority of the respondents were from the age of 18-21 years old. In the context of ethnicity, most all of the respondents were Malay. $58.6 \%$ of the respondent reported to experienced sexual harassment and lecturers were the highest propreitors followed by staff, peers, and others. As expected, most of the proprioters were male. In term of level of awareness towards sexual harassment, $57.5 \%$ of the respondent rate intermediate level of awareness. Almost half of the respondents revealed that they have been harassed at least once. More than half of the respondents not sure about the presence of policy on sexual harassment in the institution. 19 items in the questionnaire that describe the awareness towards sexual harassment experienced was adapted from the DEOC Task Force on Discrimination and Sexual Harassment, USA. Descriptive analyses on the awareness towards sexual harassment experienced were examined. Three types of sexual harassment was examined. The utmost form of sexual harassment experienced by the respondents was offensive behavior. Victims reported to sexually expressed stories or jokes that may insult them reported higher in this category. Other forms of sexual harassment received are unwanted sexual attention. It comprises of the characteristics such as attempts to create a romantic sexual relationship even though efforts to discourage it, threats or bribes to a person in order to have sexual favors and making attempts to touch, stroke, fondle or kiss the victim. Unwanted sexual attention was determined in five items in the section. The harasser's continuously asking for dates, dinner and other treats.

For this category, the harasser's determination to ask for dates, drinks, dinner, and other eventhough the victims refused seem to lead the items in the unwanted sexual attention category. It also can be concluded that all five items show only average and low mean score for the behavior. The mean scores between 1.76 and 2.24 suggests that the respondents 
received this kind of harassment was low. Apart from that, sexual coercion, for instance benefit of job (or losses) conditional on sexual cooperation, was stated in lower number. The mean scores of sexual coercion category were between $1.57-1.76$ reported the least common types of sexual harassment experienced by the respondents compared to the previous two categories. This section reports lowest percentage and mean score and the most often mention by the respondents was they being bribed with some sort of reward or special treatment to engage in sexual act.

This study also tries to find out the effects of sexual harassment to the victims. Effects of sexual harassment to respondents are divided into three categories which is education, productivity and emotional. Average mean value between 2.61 and 3.15 indicated that majority of the respondents neutral in their perception towards the effect of sexual harassment towards their education. Most agreed respond by the respondents are sexual harassment created an offensive learning environment with the mean of 3.09. In term of effects of sexual harassment towards productivity, the average mean score between 2.38 and 2.78 also shown sexual harassment gives less impact to the respondents since most of the respondents neutral in their opinion. The highest mean score for this part was 2.78 where the respondents' perceived sexual harassment affected their productivity or education performance. Sexual harassment also influences victims' emotion. Seven items related to effect of sexual harassment towards the victims emotionally was recognized. Respondents' rate their perception greater in this section compared to others with the mean score between 2.81 to 3.19. Most of the respondent feel embarrassed from the sexual harassment experienced with the highest mean of 3.19 .

Risk factor associated to sexual harassment was also recognized. These factors were classified into two; factors related to educational environment and human factor. Overall mean scores for both categories was higher with the mean value of 3.08 to 3.71 . The respondents agreed that unprofessional learning environment contributed essentially towards the incidence of sexual harassment in educational environment. Further, low moral values of the harasser perceived to have the utmost contribution to the act. Fig. 1 illustrates the conceptual framework of the study. 
Independent variable

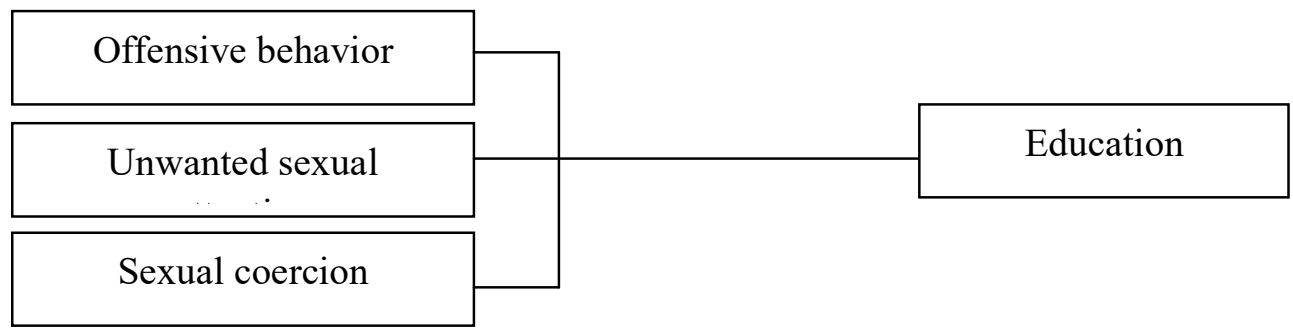

Fig.1. Conceptual framework of relationship between independent variables and dependent variable

The following hypotheses have been developed.

$\mathrm{H}^{1}$ : Offensive behaviour has a positive effects towards education

$\mathrm{H}^{2}$ : Unwanted sexual attention has a positive effects towards education

$\mathrm{H}^{3}$ : Sexual coercion has a positive effects towards education

Table 1. Correlation analysis

\begin{tabular}{|lllll|}
\hline Variables & 1 & 2 & 3 & 4 \\
\hline 1. Offensive behavior & 1.000 & & & \\
2. Unwnted sexual attention & 0.718 & 1 & & \\
3. Sexual coercion & 0.574 & 0.712 & 1 & \\
4. Education & 0.101 & 0.171 & 0.296 & 1 \\
\hline
\end{tabular}

Correlation is significant at the 0.00 level ( 2 tailed)

Pearson correlation coefficient was used to examine the relationship between offensive behavior, unwanted sexual attention, sexual coercion and effects towards education. Table 1 illustrates that overall variables value of correlation ranging from 0.101 to 0.718 . It can be concluded that, there are positive and low strength of relationship between offensive behavior, unwanted sexual attention, and sexual coercion towards the student's education. 
Table 2. Regression analysis

\begin{tabular}{|lc|}
\hline \multicolumn{1}{|c|}{ Independent variables } & $\begin{array}{c}\text { Education } \\
\text { Beta Coefficient }\end{array}$ \\
Offensive behavior & -.120 \\
Unwanted sexual attention & -.030 \\
Sexual coercion & .499 \\
$\mathrm{R}^{2}$ & .094 \\
Sig. F value & .000 \\
\hline
\end{tabular}

Significant levels: ${ }^{* *} \mathrm{p}<0.01,{ }^{*} \mathrm{p}<0.05$

In order to identify the effects of offensive behavior, unwanted sexual attention and sexual coercion towards education performance, multiple regession was performed. Table 2 shows the summary of regression analysis. The findings revealed that the $\mathrm{R}^{2}$ is 0.094 . Thus, it can be concluded that offensive behavior, unwanted sexual attention and sexual coercion influence student's education at $9.4 \%$.

Offensive behavior $(\beta=-.120, p<0.305)$ and unwanted sexual attention $(\beta=-.030, p<0.810)$ have no signigicant effect towards student's education. However, offensive behavior $(\beta=$ 0.499, $p<0.000$ ) stated to have significant effect towards education. Hence, only hypothesis 3 was accepted meanwhile hyphoteses 1 and 2 were rejected.

\section{CONCLUSION}

Higher education institution possesses an exclusive position in order to answer and avert sexual harassment. Findings revealed that there are presences of sexual harassment incident in academic setting. With $58.6 \%$ of students' reported to be harassed, it was an alarming number and it is not impossible the number come to be larger in the future. The three variables namely offensive behavior, unwanted sexual attention and sexual coercion become important predictors that may build challenges towards lead to sexual harassment occurrence. Findings revealed that, sexual coercion importantly influenced student's education. Females were more likely than males to receive sexual harassment and tremendously, men were the committers sexual harassment reported in the survey. Thus, in dealing with a specific internal rules and procedures in the university, top management in every higher education institution particularly in Malaysia need to have specific in-house policy and procedure in dealing with 
cases of sexual harassment. Initiative made by the University of Malaya by forming the Sexual Harassment Complaint Bureau should be resembled by other universities. This bureau provides support to victims in handling sexual harassment incidents on campus besides to promote clear and available information on the sexual harassement policies, procedures as well support services. Subsequently, it is the obligation of the universities to offer a safe yet condusive learning environment for their students and staff. Future work of this study is to educate the students on the strategy to protect thierself from sexual harassment by providing apps for them to learn through it at anywhere and anytime.

\section{ACKNOWLEDGEMENTS}

The authors are grateful to Universiti Teknologi MARA (UiTM), Terengganu Malaysia for supporting this research under Special Interest Group (SIG) Grant (600-UiTMKD-PJI/RMU/SS/DANA SIG 5/2/1-Dss07/2016). Also, the deepest humble gratitude is goes to Department of Research, Industrial Linkages, and Alumni, UiTM Terengganu, Malaysia for providing publication opportunities, lab facilities, and educational support towards the accomplishment of this research.

\section{REFERENCES}

[1] Equal Employment Opportunity Commission (EEOC). Sexual harassment, 2017

[2] Ministry of Human Resource. Code of Practice, 1999

[3] Khan R, Brewer G, Kim S, Centifanti, L C M. Students, sex, and psychopathy: Borderline and psychopathy personality traits are differently related to women and men's use of sexual coercion, partner poaching, and promiscuity. Personality and Individual Differences, 2017, $107,72-77$

[4] Shanshan H, Sandra T. Perceived female infidelity and male sexual coercion concerning first sex in Chinese college students' dating relationships: The mediating role of male partners' attachment insecurity. Personality and Individual Differences, 2017, 111, 146-152.

[5] Pérez-Peña R. College groups connect to fight sexual assault. The New York Times, 2013.

[6] Strout T, Amar A F, and Astwood K. Women's center staff perceptions of the campus climate on sexual violence. Journal of Forensic Nursing, 2014, 10(3):135-43. 
[7] Nor S M. Terpedaya janji manis punca berlaku ganggguan seksual. Mstar, 2017

[8] Lauren P, Brian S. University professor accused of sexual harassment of 14 students. USAtoday, 2017

[9] University Sexual Assault Report. Half of all students harassed at least once in 2016, 2017

[10] Ismail M N, Lee K C, Chen F B. Factors influencing sexual harassment in the Malaysian workplace. Asian Academy of Management Journal, 2007, 12 (2):15

[11] Ahmad S A A. Undang-undang gangguan seksual di Malaysia. Malaysia: PTS Publication \& Distributors, 2005.

[13] Cantor D, Fisher B, Chibnall S, Townsend R, Lee H, Bruce C, and Thomas G. Report on the AAU campus climate survey on sexual assault and misconduct. Association of American Universities, 2015

[14] Richard W, Siti Hajar A B, Noralina O, Mettilda J, Nooreen P, Madeleine Y. Evaluation of a school-based sexual abuse prevention curriculum in Malaysia. Children and Youth Service Review, 2012, 34(1):119-125

[15] Basu T M, Priscilla P. Sexual harassment in academic institution. Journal of Psychosocial Research, 12(1):33-40

[16] Sexual assault and harassment rife at university. Australian Nursing and Midwifery Journal, 2017, 25(3):6

[17] Melissa K. Education department to overhaul process for sexual assault cases. Wall Street Journal, 2017, 1

[18] Christopher U, Chika S. Sexual harassment comes on age: A comparative analysis of the United States and Japan. Sociological Quarterly, 2009, 50(2):201-234

[19] Fribog M K, Hansen J V, Aldrich P T, Folker A P, Kjaer S, Nielson M J D, Rugulies R, Madsen I E H. BMC Publich Health, 2017, 17, 1-12

\section{How to cite this article:}

Rapidah O A S, Shafini S N, Khalid M A, Masliza M Z, Nurulnadwan A. Sexual sexual harassment in campus: Awareness, risk factor, and effect among students in higher learning institutions. J. Fundam. Appl. Sci., 2017, 9(5S), 1087-1096. 